This is a self-archived - parallel published version of this article in the publication archive of the University of Vaasa. It might differ from the original.

\title{
Talent responses to talent status awareness- Not a question of simple reciprocation
}

\author{
Author(s): Ehrnrooth, Mats; Björkman, Ingmar; Mäkelä, Kristiina; Smale, \\ Adam; Sumelius, Jennie; Taimitarha, Susanna \\ Title: $\quad$ Talent responses to talent status awareness-Not a question of \\ simple reciprocation \\ Year: $\quad 2018$ \\ Version: final draft (post print, aam) \\ Copyright Wiley
}

\section{Please cite the original version:}

Ehrnrooth, M., Björkman, I., Mäkelä, K., Smale, A., Sumelius, J., \& Taimitarha, S. (2018). Talent responses to talent status awareness-Not a question of simple reciprocation. Human Resource Management Journal, 28(3), 443-461. https://doi.org/10.1111/1748-8583.12190 


\title{
Talent Responses to Talent Status Awareness - Not a Question of Simple Reciprocation
}

\author{
Mats Ehrnrooth, Dr \\ (corresponding author) \\ Hanken School of Economics, Department of Management and Organization \\ P.O. Box 479, FIN-00101 Helsinki, Finland \\ Tel.+358 294313420, Email: mats.ehrnrooth@hanken.fi \\ Ingmar Björkman, Professor \\ Aalto University School of Business \\ P.O. Box 21210, 00076 Aalto, Finland \\ Tel.+358 40704 0291, Email: ingmar.bjorkman@aalto.fi \\ Kristiina Mäkelä, Professor \\ Aalto University School of Business \\ P.O. Box 21210, 00076 Aalto, Finland \\ Tel.+358 40559 3454, Email: kristiina.makela@aalto.fi \\ Adam Smale, Professor \\ University of Vaasa, Department of Management \\ P.O. Box 700, 65101 Vaasa, Finland \\ +358 29449 8446, Email: adam.smale@uva.fi \\ Jennie Sumelius, Dr \\ University of Vaasa, Department of Management \\ P.O. Box 700, 65101 Vaasa, Finland \\ Tel.+358 29449 8000, Email: jennie.sumelius@uva.fi \\ Susanna Taimitarha, M.Sc. \\ Hanken School of Economics, Department of Statistics \\ P.O. Box 479, FIN-00101 Helsinki, Finland \\ Tel.+358 40352 1371, Email: susanna.taimitarha@hanken.fi
}

The full citation to the published version of this paper is:

Ehrnrooth M., Björkman I., Mäkelä K., Smale A., Sumelius J., \& Taimitarha, S. (2018). Talent responses to talent status awareness-Not a question of simple reciprocation. Human Resource Management Journal, 28: 443-461. https://doi.org/10.1111/1748-8583.12190. 


\title{
Talent Responses to Talent Status Awareness - Not a Question of Simple Reciprocation
}

\begin{abstract}
How to manage talent effectively is a key question in organizations. Yet, we still know relatively little about talent's psychological reactions to their exclusive status. Based on psychological contract theory and research on status, this study analyzes a sample of 321 employees identified as talent by their organizations, only some of whom were aware of their exclusive talent status. The results provide evidence that talent status awareness moderates the relationship between a range of employer inducements and talent obligations, such that it increases the importance of some inducements while diminishing that of others. The study contributes to the talent management literature by isolating specific effects of talent status awareness and calling into question extant evidence of its direct positive effects on talent attitudes. The findings also have implications for talent status communication, talent management and future theorizing of talent reactions to their exclusive status.
\end{abstract}

Keywords: Talent management, psychological contract, status, performance management. 


\section{INTRODUCTION}

Talent management (TM), defined as an exclusive form of workforce management (GallardoGallardo, Dries \& Gonzalez-Cruz, 2013), is considered to be one of the most important human resource management challenges in organizations (Cappelli \& Keller, 2014). Yet, while the practitioner-oriented literature abounds with topics related to TM, empirical academic research has only recently begun to gain momentum (Dries, 2013; McDonnell, Collings, Mellahi \& Schuler, 2017). One strand of this emerging academic literature focuses on employees' psychological reactions to TM (Dries, Forrier, Vos \& Pepermans, 2014; Malik and Singh, 2014). We extend this research by studying how talent status awareness influences the way talent react to a range of management practices, or employer inducements as defined below . By so doing, we also create a bridge between extant research focusing on individual talent and research on how to manage talent (McDonnell et al., 2017).

Research suggests that both mere belief (Björkman, Ehrnrooth, Mäkelä, Smale \& Sumelius, 2013) and more certain knowledge (Gelens, Hofmans, Dries \& Pepermans, 2014) of being identified as talent are associated with positive employee attitudes. Inversely, research also indicates that ambiguity (Dries \& De Gieter, 2014) and incongruent employer-employee perceptions (Sonnenberg, Zijderveld \& Brinks, 2014) concerning talent status can be problematic. Despite this, a surprising number of organizations still choose not to communicate clearly to talent about their special status (Dries \& De Gieter, 2014; cf. Silzer \& Church, 2010; Björkman et al., 2013). This choice is partly due to concerns that transparency will increase expectations, self-satisfaction and complacency among those identified as talent (Dries \& De Gieter, 2014; cf. Silzer \& Church, 2010). Some support for this can be found in research on status and status dynamics (Bothner. Kim \& Smith, 2012; Chen, Peterson, Phillips, Podolny \& Ridgeway, 2012; cf. Kehoe, Lepak \& Bentley, 2016), but these reactions remain understudied within TM. To address this important research gap and understand better the "psychological dynamics" of TM (Dries et al., 2014: 569), we aim to answer the following research question: Do talent that are aware of their exclusive status 
respond differently to employer inducements compared to talent that are unaware? In so doing, we also seek to address the important practical question of the consequences of informing talent about their status.

In the present study we define 'talent' as employees whom the employer considers to be potential future leaders, i.e. high potentials (Gallardo-Gallardo et al., 2013; cf. Gelens et al., 2014), and status as "the prestige, respect, and admiration that individuals enjoy in the eyes of others" (Lount \& Pettit Jr., 2012: 15; cf. Pettit, Yong \& Spataro, 2010). Conceptually, we introduce the notion of "talent status awareness' to help us make the distinction between identified talent that are unaware of their talent status, and those that are actually aware of it. Empirically, we analyze a sample of 321 employees within eight Finnish corporations who have all been formally identified by the organization as talent. Within this sample, only $45 \%$ were personally aware of their talent status whereas the remaining $55 \%$ of the sample were unaware. This provides an ideal empirical setting for isolating and studying the moderating effects of talent status self-awareness.

Theoretically, our research is primarily grounded in psychological contract theory (Coyle-Shapiro \& Conway, 2005; Rousseau, 1995) and its central framework of employer inducements and employee obligations. Here, employer inducements refer broadly to various management practices or forms of organizational investments in employees, such as rewards, recognition and support, whereas employee obligations refer to employees' commitment to reciprocate such inducements (Coyle-Shapiro \& Conway, 2005; Lee, Liu, Rousseau, Hui \& Chen, 2011). Talent commitment to reciprocate organizational inducements is a cornerstone of TM, and thus crucial to understand, given that the primary goals of TM are to increase the retention and commitment of talent, and to accelerate their development (DeGieter et al., 2014). To connect to these goals we use a construct of obligations that focuses on talents' commitment to accept dynamic performance demands and to develop their value for the organization, hereafter referred to as 'talent obligations'. While psychological contract theory provides the basic framework within which we examine how status awareness changes the effect of organizational inducements on talent obligations, we also build on research into the effects of status and status dynamics 
(Chen et al., 2012; Bothner et al., 2012; Marr \& Thau, 2014). This research stream sheds light on a range of psychological reactions to status, status gain and status loss, that help to explain how talent status awareness can change the terms of the psychological contract and thereby the way in which talent react to organizational inducements.

Our study contributes to the emerging literature on psychological reactions to TM (Björkman et al., 2013; Gelens et al., 2014; Malik and Singh, 2014; Sonnenberg et al., 2014) by isolating moderating effects of talent status awareness among identified talent. The results call into question extant research on the direct motivational effects of talent status awareness and offer substantive evidence for the conjecture that talent attitudes may not be "only affected by the high potential label itself" but rather by a combination of talent status and organizational inducements (Gelens et al., 2014: 170). This extends extant theorizing of the effects of talent status awareness. Our results also shed further light on the

practical consequences of transparency in communication about TM (Dries \& De Gieter, 2014), consistent with organizational concerns about the undesirable effects of talent status awareness, such as increased expectations, self-satisfaction and complacency. Finally, our study brings to the fore questions about the relative merits of tournament-style TM (Björkman et al., 2013; cf. Bothner, Kang \& Stuart, 2007) versus the tendency for status hierarchies to "remain stable and be self-sustaining" (Chen et al., 2012: 302).

\section{EXTANT RESEARCH ON EMPLOYEE REACTIONS TO TALENT STATUS}

\section{AWARENESS}

Prior research suggests that subjectively perceiving that one has been identified as talent (Björkman et al., 2013) and de facto being identified as talent (Gelens et al., 2014) are associated with positive employee attitudes. Other research points to more complex interaction effects between talent status and organizational inducements. First, Marescaux, De Winne and Sels (2013) show that while differentiation among employees tends to have positive attitudinal effects, these effects can be attenuated by perceptions 
of negative favorability (i.e. "others unduly get more than me"), and may even turn into negative effects. Relatedly, while Sonnenberg et al.'s (2014) provide support for the direct influence of talent status perceptions on employee attitudes, their results also suggest that this influence may interact with employer inducements. They show that incongruence in employer-employee perceptions of talent status, in essence falsely believing that one has talent status, is positively correlated with psychological contract fulfilment, but that this association is negative when controlling for TM practices.

On the whole extant research suggests that perceived talent status is associated with positive employee attitudes (cf. Cappelli \& Keller, 2014; cf. McDowell et al., 2017) and that transparent communication is important (Sonnenberg et al., 2014). However, some of this research also suggests that status perceptions may influence employee reactions to organizational inducements/management practices in more complex ways (cf. Gelens et al., 2014).

Given the findings pointing to the positive reactions to talent status, it appears counter-intuitive that "less than one in three organizations disclose information about their high potential programs to employees - and when they do, information is often exchanged in a very informal manner" (Dries et al., 2014: 137; cf. Bournois and Rousillon, 1992; Dries \& Pepermans, 2008; Silzer \& Church, 2010). The degree to which employers openly communicate talent status is likely to be even lower in organizations from the Nordic countries due to the uneasy coexistence of strong societal values of egalitarianism and exclusive organizational investments in talent. For example, none of the eleven MNCs studied by Björkman et al. (2013) had a policy of openly communicating talent status. This wariness to communicate talents status supports the possibility that research is yet to uncover the complexity of the effects of talent status awareness.

What may concern organizations is that letting talent know about their exclusive status may raise their expectations (Dries and De Gieter, 2014; Dries \& Pepermans, 2008), create arrogance (Pfeffer, 2001) and complacency - also known as the "the crown prince syndrome" (Göbel-Kobialka, 1998) and even decrease their performance (Silzer \& Church, 2010). Based on qualitative data, Dries and De 
Gieter (2014) provide indicative evidence that talent status is associated with expectations of special treatment. Recent research on status dynamics and tournament-like forms of organization provide additional support for such less desirable reactions, including expectations of special treatment, selfsatisfaction, performance loss, and unhealthy competition (Chen et al., 2012; Marr \& Thau, 2014).

Even though the decision not to communicate talent status openly may be rational due to the above kinds of concerns, it involves what Dries and De Gieter refer to as a paradoxical ambiguity since one of the basic purposes of TM is to achieve "retention and commitment through differentiation" (2014: 137). This purpose is less likely to be achieved without communication of talent status. The above concerns and the fact that organizations, even in the absence of explicit communication, tend to signal information about talent status to their talent through different channels (Dries \& De Gieter, 2014) makes it even more important to increase our understanding of talent reactions to status awareness.

To contribute to this understanding, the present study focuses on the interaction effects of status awareness and employer inducements, effects suggested by some of the above research but hitherto underexplored in the TM literature.

\section{THEORY AND HYPOTHESES}

\section{Inducements, talent obligations and talent status awareness}

In this section we briefly explicate the theoretical foundation of our model, the related constructs we use and the model we test, after which we present the individual hypotheses.

Psychological contract theory (Rousseau, 1995) focuses on the "thought processes underlying how employees judge their employer's actions, how they respond to their treatment, and how they react to changes in their conditions of employment" (Lee et al., 2011:202). Regarding changes or differences in talent's conditions of employment, we focus on the construct of talent status awareness. In terms of employee reactions, we focus on talent obligations. And in terms of employer actions, or their treatment of employees, we focus on three types of inducements: the employer's psychological contract fulfillment, 
two aspects of performance management, and the provision of leadership development practices. In this paper, we treat the employer's psychological contract fulfillment as an inducement in its own right based on the argument that it is a clear way to "signal investment in employees and recognize contributions" (Coyle-Shapiro and Shore, 2005, p. 776). Whilst psychological contract fulfillment may also play a mediating role (Lee et al., 2011), this falls outside the scope of the present study.

The focal inducements are all likely to be of key importance in managing talent obligations: Psychological contract fulfilment because talent are likely to be particularly sensitive to the organization's fulfilment of its part of the psychological contract (Dries \& De Gieter, 2014), performance management because, as high performers, talent are likely to appreciate systematic performance management (e.g. Shaw, Dineen, Fang \& Vellella, 2009), and the provision of leadership development practices since talent are likely to expect opportunities for development (Dries \& De Gieter, 2014). What we do not know, and is of focal interest in the present study, is how talent status awareness influences talent responses to these inducements.

In order to understand this better we complement our argumentation based on psychological contract theory by building on research into status and status dynamics (Chen et al., 2012). Whilst the arguments stemming from psychological contract theory are grounded in the norm of reciprocity (Liu et al., 2011), status research helps us understand the complexity of status-related effects, more specifically the potential for status to change the terms of reciprocity involved in the psychological contract between talent and the employer (cf. Dries \& De Gieter, 2014). Recent research on status highlights that status can be both an asset and a liability (e.g. Chen et al., 2012; cf. Kehoe \& Tzabbar, 2015). For example, status can lead directly to psychological rewards such as self-esteem (Pettit et al., 2010) and several other benefits (Chen et al., 2012), however it can also give rise to self-satisfaction, indifference and reduced agency (Bothner et al., 2007). Whether such reactions are likely consequences of subjective talent status awareness, and whether they are likely to influence how self-aware talent respond to the above mentioned employer inducements, is what we set out to examine. 
Building on this theoretical framework, our focal argument is that the effects of employer inducements on talent obligations will be moderated by talent's awareness of their exclusive status due to psychological reactions that are likely to arise from that awareness. Our four moderation hypotheses, presented below, are depicted in Figure 1.

\section{INSERT FIGURE 1 ABOUT HERE}

\section{Talent status awareness, employer psychological contract fulfillment and talent obligations}

The psychological contract, from the employee viewpoint, concerns "expectations that emanate from perceived implicit or explicit promises by the employer" (Robinson, 1996: 575) and is defined as "individual beliefs, shaped by the organization, regarding terms of an exchange agreement between individuals and their organization" (Rousseau, 1995: 9). We know that employee perceptions of their employer's psychological contract fulfillment are an important antecedent to employee obligations (Lee et al., 2011).

The act of making talent aware of their status has been viewed as a "critical incident in the (re)formation of the exchange relationship" and the psychological contract between the talent and their employer (Dries \& De Gieter, 2014: 139). Talent status signals the employer's belief in the exclusive value of the employee, often communicated in terms of the employee's future role and opportunities within the organization. The norm of reciprocity, central to psychological contract theory, implies that both parties of the contract continuously expect "resources in return for what they offer" (Hom, Tsui, Wu, Lee, Zhang, Fu \& Li, 2009: 278). This tends to be especially true for high performers (Shaw et al., 2009), which talent are likely to be. Thus, we argue that when high performing talent become aware of their exclusive status, and thus their exclusive value to the employer, they are likely to expect to benefit from it by raising their expectations regarding subsequent employer actions (Dries et al., 2014). Rather 
than simply making talent reciprocate with positive attitudes as a form of gratitude to their talent status (Björkman et al., 2013; Gelens et al., 2014), we thus suggest that talent status awareness is likely to change the terms of the psychological contract, making talent more demanding and sensitive to the employer's psychological contract fulfilment.

The likelihood of this outcome is supported by research on status dynamics which has shown that an increase in status is associated with individuals' increased self-esteem (Pettit et al., 2010) and confidence in their own value (Bothner et al., 2012). This should further strengthen the tendency among self-aware talent to increase their demands for value in return for what they offer to the employer, and thus increase their sensitivity concerning the degree to which the employer fulfils its part of the psychological contract.

This leads us to put forth the following hypothesis:

Hypothesis 1: Talent status awareness positively moderates the relationship between the employer's psychological contract fulfillment and talent obligations such that the relationship is stronger for talent that are aware of their status compared to those that are unaware.

\section{Talent status awareness, performance management and talent obligations}

Our next two hypotheses are both related to performance appraisal. As an important performance management-related inducement and a central aspect of high performance work practices (Takeuchi, Lepak, Wang \& Takeuchi, 2007; Lepak \& Snell, 2002), performance appraisal serves "as the motivational bases for employee behavior" (Chiang \& Birtch, 2010: 1367). We argue that performance appraisal is an important inducement in at least two specific ways. On the one hand, it serves to guide, support and put pressure on employees by way of target setting and the provision of evaluative feedback. This is an important part of the motivational aspect of performance appraisals (Rynes, Gerhart \& Parks, 2005). On the other hand, performance appraisal serves as an evaluation-based, allocative mechanism 
to ensure appropriate rewards for performance. This connection between performance evaluation and rewards is important in determining employee responses (Rynes et al., 2005). Furthermore, as both play an important role in assuring appropriate performance-based rewards, they should be especially important for high performers who tend to prefer rewards for performance (Shaw et al., 2009). We can thus assume that both are important inducements for talent and thus positively related to their obligations.

Based on this, we first turn to the moderated relationship between talent obligations and performance appraisal linked to rewards. We argue that talent status awareness is likely to strengthen this relationship since status awareness should increase talent's preference for performance-based inducements and thus their responsiveness to them. This builds on the argumentation about an increased sensitivity to psychological contract fulfillment, but concerns a more specific sensitivity concerning performancebased rewards.

As noted, the communication of talent status can change the terms of the exchange relationship by making talent more self-confident (Dries \& De Gieter, 2014; Silzer \& Church, 2010). Research on status effects supports this with findings that show how status gain makes individuals more self-efficacious, i.e. more self-assured of their ability to perform (Bothner et al., 2012). This is partly attributable to the positive (self-fulfilling) effects of external social expectations faced by high-status individuals (Berger, Fisek, Norman \& Zelditch Jr, 1977; Webster \& Entwisle, 1976; cf. Bothner et al., 2012), which forms the basis of the so-called Pygmalion effect (Tierney \& Farmer, 2004; Whiteley, Sy \& Johnson, 2012). Talent status clearly signals such expectations in the talent's performance and potential (cf. Swailes \& Blackburn, 2016). This should make self-aware talent more self-assured of their ability to perform and gain from performance-based rewards than unaware talent. In addition, due to their increased selfconfidence, self-aware talent are also more likely than unaware talent to view their own expected benefit from performance-based rewarding as an important source of reinforcement of their perceived exclusivity and positive distinctiveness. In addition to these status-related arguments, the importance of perceived reciprocity, posited by psychological contract theory to be central to how 
"employees...respond to their treatment" (Lee et al., 2011: 202), supports the argument that performance-based rewards should be more highly preferred by self-aware talent and thus have a stronger effect on their obligations. The argument is that their increased confidence in their ability to deliver exclusive value to the organization should make them feel a stronger sense of entitlement to differentiated rewards.

Based on both status research and psychological contract theory we thus put forth the following hypothesis:

Hypothesis 2a: Talent status awareness positively moderates the relationship between performance appraisal that links evaluation to rewards and talent obligations such that the relationship is stronger for talent that are aware of their status compared to those that are unaware.

Next, we focus on the moderated relationship between talent obligations and the inducement of target setting and evaluative feedback in performance appraisal. Here we extend the argument that talent status awareness is likely to make talent more self-confident to argue that in TM systems it is also likely to make them more self-satisfied, and thus less interested in and less responsive to target setting and evaluation in performance appraisal.

Corporate TM systems usually involve annual talent reviews (see e.g. Gelens et al., 2014), in which the performance, development and future career moves of identified talent are discussed. Within a transparent and dynamic, tournament-style TM system (Bothner et al., 2007; cf. Bendersky \& Shah, 2012), one would expect that those identified as talent become more interested in continuous target setting, performance evaluation and feedback. In such TM systems, self-aware talent should be particularly interested in understanding what they need to do in order to comply with their part of the psychological contract and thus maintain their talent status. However, as noted, most employers avoid 
transparent talent communication (Silzer \& Church, 2010; Dries \& De Gieter, 2014) and thus tournament-style talent status systems. We argue that this is likely to have profound implications for the attitudes of self-aware talent and the psychological contracts with their employers.

Whilst talent status awareness is likely to make talent more confident in their ability and their value to the employer, the literature also suggests that it may make them complacent and even arrogant (Dries \& De Gieter, 2014; Göbel-Kobialka, 1998; Silzer \& Church, 2010; Pfeffer, 2001). Building on research in sociology that provides support for these status-related effects, Bothner et al. argue that "the positive sentiments of relative advantage" among "higher-status actors" tend not only to lead to positive effects, but also to negative effects in terms of indifference, reduced agency and "detrimental feelings of selfsatisfaction" (2012: 419). The TM literature also contains some indicative empirical evidence of a tendency among self-aware talent to become complacent and self-satisfied:

“Once you're on that [high potential] list, and you're not satisfied in your job anymore [... .] they'll say 'OK, let's look at all possible positions for you here at [company], what would you like to do next" [...] I feel so comfortable in this situation" (Dries \& De Gieter, 2014: 146; italics added).

The increased self-confidence and self-efficacy that tends to follow status gains (Bothner et al., 2012) may make self-aware talent think that they know the drill in their current job and feel relatively secure about their talent status. Status-related arrogance, complacency and comfortability may all follow from this. We argue that these reactions are especially likely to take place within a non-tournament-style TM system which, as noted above, is likely to be the rule rather than the exception (cf. Chen et al., 2012). Under these circumstances talent status awareness is likely to weaken the perceived danger of not being able to deliver, and thereby the need for target setting and evaluative feedback. This is likely to translate into a weaker effect of this type of performance management on the obligations of self-aware talent, as 
compared to those unaware of their status, who are more eager to show they can perform. This leads us to hypothesize the following:

Hypothesis 2b: Talent status awareness negatively moderates the relationship between target setting and evaluative feedback in performance appraisals and talent obligations such that the relationship is weaker for talent that are aware of their status compared to those that are unaware.

\section{Talent status awareness, leadership development practices and talent obligations}

Leadership development practices have been referred to as TM practices and defined as "communication mechanisms, ones that signal the expectations of the organization regarding the desired behaviors of employees, and also the organization's reciprocal promises to these employees" (Sonnenberg et al., 2014: 272). Extant research indicates that talent expect and respond positively to inducements in the form of such practices (Dries \& De Gieter, 2014; Khoreva, 2015). We go beyond this by arguing that talent status awareness will positively moderate the relationship between leadership development practices and talent obligations.

As already discussed, becoming aware of one's talent status is likely to shift the balance of the psychological contract in such a way that the self-aware talent will expect more investments in exchange for their acknowledged exclusive value (cf. Dries and De Gieter, 2014). Leadership development practices represent very concrete investments in talent and are thus especially likely to be viewed as key sources of balance in the psychological contract between self-aware talent and the employer. Based on this we argue that self-aware talent are not only likely to expect and respond positively to such practices, but that they will expect more of them and react more strongly to their presence /absence, than unaware talent. 
From a status perspective, leadership development practices are also likely to represent visible affirmations of exclusive status within the organization. This is likely to become more important for selfaware talent as their expectations of various rewards simply "by virtue of their status" is likely to be higher than those of unaware talent (Lount \& Pettit, 2012: 17; Swailes \& Blackburn, 2016). This should also make self-aware talent react more strongly to such practices, as compared to unaware talent.

We note that this causal logic is quite different from the one related to target setting and evaluation in performance appraisal in non-dynamic TM systems. The difference is grounded in the fact that target setting and evaluation primarily helps talent understand how they perform and should perform in their current job, thus representing a form of help which is likely to become less relevant the more selfconfident, self-satisfied and complacent talent becomes. This is in contrast to leadership development practices, which not only represent more concrete and visible status-enhancing rewards, but also help talent prepare for more challenging future roles. Such preparation is likely to become more relevant and important for self-aware talent, almost regardless of their confidence, since they are more likely than unaware talent to expect such future challenges.

Based on this we put forward our final hypothesis:

Hypothesis 3: Talent status awareness positively moderates the relationship between leadership development practices and talent obligations such that the relationship is stronger for talent that are aware of their status compared to those that are unaware.

\section{METHOD}

\section{Sample}

The data were collected in 2012 through a web-based survey by an executive education unit at a leading Nordic business school based on a questionnaire developed by the authors. 76 Finnish companies, among those 11 that had participated in an earlier collaboration on leadership development with the education unit, were contacted for the present talent survey. This resulted in eight companies participating, their 
size varying between of $1.1-9.7$ billion EUR in turnover. The companies represented five different industries, industrial machinery and services, pharmaceutical wholesale, banking, media and IT services. The survey was sent out to 589 talent, in this case employees who had been formally identified by the organizations as high-potentials for top management/management team positions by 2020 . The sampled individuals thus represent talent defined as high-potentials (Gelens et al., 2014; cf. Malik \& Singh, 2014). Anonymity was guaranteed to the respondents in order to minimize social desirability bias. 321 useful responses were received, the effective response rate of the surveyed talent thus being $55 \%$. None of the organizations had an explicit organizational policy of openly communicating talent status. As a result, only $45 \%(\mathrm{~N}=144)$ of the identified talent were aware of their status as high potentials. Sample demographics are presented in Table 1.

\section{INSERT TABLE 1 ABOUT HERE}

\section{Measures}

\section{Dependent variable}

Talent obligations was measured with six items based on Rousseau (2000). The construct captures talents' commitment to accept dynamic performance demands and to develop their value for the organization. We first asked the talent to rate their commitment $i$ ) to accept increasingly challenging performance requirements; ii) to accept new and different performance requirements iii) to adjust to changing performance demands. We also asked them to rate their commitment i) to seek out developmental opportunities that enhance your value to your employer; ii) to build skills to increase your value to your employer; iii) to make yourself increasingly valuable to your employer. These measures are closely related to the key goal of TM to "accelerate the development of employees with high potential" (Dries \& De Gieter, 2014: 139) and form two key employee obligations 
dimensions of the "balanced" psychological contract (Rousseau, 2000: 4, 9-10). The operationalization of each dimension was based on the three first mentioned, well-functioning items in the final recommendations in the Appendix in Rousseau (2000). The Cronbach's alpha for the full six-item (seven-point Likert scale) construct was 0.89.

\section{Independent variables}

Psychological contract fulfillment was measured with three items based on Robinson and Morrison (2000). We asked the talent to rate, on a seven-point Likert scale, their experience concerning the following: i) All the promises made by my employer during recruitment have been kept so far, ii) I feel that my employer has fulfilled the promises communicated to me, iii) So far my employer has done an excellent job of fulfilling its promises to me. The alpha value for this construct was 0.95 .

Connection between performance appraisal and rewards was operationalized by two items tapping into the respondent's experience as follows: i) Performance appraisals are used for reward decisions; ii) Performance appraisals are used for promotion decisions. The Cronbach's alpha was 0.73. The items were developed by the current authors to capture the link between performance appraisal and its consequences for rewards. It focuses on an aspect of performance appraisal that has gone largely unnoticed in extant research, answering to the call for more research on the effects of "linking PE [performance evaluation] to pay or other rewards" (Ryan et al., 2005:573).

Target setting and evaluative feedback in performance appraisal was operationalized by four items tapping into the respondent's experience: i) Performance appraisals are used for setting performance targets; ii) Performance appraisals are used to provide feedback on performance; iii) Performance appraisals are used for determining development needs; iv) Performance appraisals are used to provide feedback on development. The Cronbach's alpha was 0.87 . The items were adapted based on measures of performance appraisal as part of high-performance work practices (Takeuchi et al., 2007; Lepak \& Snell, 2002) and the key elements of motivational performance appraisals (Rynes et al., 2005). 
Leadership development practices was measured by 16 items that MNCs typically use for leadership development (see e.g. Evans, Pucik and Björkman, 2010). The construct captured practices related to five dimensions: mobility, short-term assignments, special projects, feedback, coaching and mentoring, and formal training programs. Sample items are: Moving to new positions (for at least one year) in other division/business unit (Mobility); Implementing reorganizations (Special projects). Overall, it compares well to the construct of TM practices used by Sonnenberg et al. (2014) and the practices implemented in the organization studied by Gelens et al. (2014). We carried out an initial validation of our 16-item construct by performing confirmatory factor analyses (CFAs) with Mplus (Muthén \& Muthén, 1998-2007). We first specified a model with the expected five first-order dimensions. This first-order model did not satisfactorily fit the data based on Williams, Vandenberg, and Edwards (2009). Informed by this model we excluded the three items measuring the dimension 'Shortterm assignments' which were not distinct enough from the items measuring the dimension 'Mobility', yet not similar enough to load on the same dimension. The resulting four-dimensional 13-item measurement model of leadership development practices exhibited good fit $\left(\chi^{2}(59)=128.663, p=\right.$ 0.000; $C F I=0.933 ; R M S E A=0.066 ; S R M R=0.050)$. Below, we offer further validation of the convergent and discriminant validity of this construct, including a second-order factor model. The Cronbach's alpha for the full original scale was .89 and for the reduced 13-item scale .87 . The full measurement instrument can be obtained from the authors.

\section{Moderator}

Talent status awareness was measured by the question 'Are you formally identified by your corporation as belonging to a talent pool/group of high potentials or similar?' This variable thus captures respondents' subjective beliefs about having been identified as talent by the organization. Identified talent may be aware of their status in one way, i.e. by correctly perceiving that they have talent status. However, they may be unaware in two different ways - either by incorrectly perceiving they do not 
have talent status or simply by not knowing whether they have that status or not. In operationalizing talent status awareness we therefore used the response categories of 'Yes', 'No', and 'Don't know'. Since the number of talent in the 'No' category was low (11\% of the sample), and did not show any differences in reactions compared to the 'Don't know' category, we merged the two into one category of unaware talent. Talent status awareness was thus operationalized as a dichotomous variable (Aware $=1 ;$ Unaware $=0)$.

\section{Control variables}

In addition to using the MNC as a blocking variable in the analysis (see below), we controlled for respondent gender, age, tenure and nationality. Gender was measured as $1=$ Male, $0=$ Female. Age was measured with the following categories, $1=$ less than 30 years, $2=31-35$ years, $3=36-40$ years, $4=41$ $45,5=46-50$ and $6=$ over 51 years. Tenure in corporation was measured with the following categories: $1=0-6$ months, $2=7-12$ months, $3=1-2$ years, $4=3-5$ years, $5=6-10$ years, $6=$ over 10 years. The nationality of the respondent was measured by assigning a dummy variable for each nationality. Groups are used for age and tenure. All control variables are thus categorical factors.

Descriptive statistics are exhibited in Table 2. It shows that all bivariate correlations between the independent and the dependent variables are significant and in the expected directions, suggesting that all variables are important for talent.

- INSERT TABLE 2 ABOUT HERE -

\section{ANALYSES}

\section{Validation}

To analyze the validity of all our key constructs we performed a CFA with Mplus (Muthén \& Muthén, 1998-2007). We thus specified a model with the expected three unidimensional first-order constructs 
(Psychological contract fulfillment; Performance appraisal - target setting and evaluative feedback; Performance appraisal - connection to rewards) together with the two multidimensional second-order constructs (Talent obligations with two first-order dimensions; Leadership development practices with four first order dimensions). Based on the criteria specified by Williams et al. (2009) this complex CFA exhibited good fit with the data $\left(\chi^{2}(335)=688.721, p=0.000 ; C F I=0.931 ; R M S E A=0.057 ; S R M R\right.$ $=0.057)$ and thus offered strong evidence of discriminant and convergent validity of our constructs, including further support for the reliability of the measures.

The ICC values for the organizational level were between .05 - .06 (ICC1) and .69 - .75 (ICC2). Based on LeBreton and Senter (2008) these values, in particular ICC1, make it relevant to account for the organizational-level nestedness of our data. Therefore, we conducted the regression analyses using Linear Mixed Modeling in SPSS with the organization $(\mathrm{N}=8)$ as a blocking variable. ${ }^{1}$

\section{RESULTS}

Model 1 (Table 3) shows that the random intercept is significant, showing the appropriateness of using the organization as a blocking variable to exclude between-organization variance in our individuallevel analyses. When we include the controls and all independent variables in Model 2, none of the control variables are significant, and neither is 'talent status awareness'. This model offers support for the importance of our inquiry in suggesting that status awareness alone cannot explain talent obligations, despite the fact that self-aware talent tend to express higher obligations (Table 2). Model 3 offers support for three $(\mathrm{H} 1, \mathrm{H} 2 \mathrm{~b}, \mathrm{H} 3)$ of our four hypotheses about the moderation effects of talent status awareness.

- INSERT TABLE 3 ABOUT HERE -

\footnotetext{
${ }^{1}$ Although no data were aggregated, upon a reviewer request we calculated rWG values. They varied between .55 and .81
} 
In Hypothesis 1 we proposed a moderating effect of talent status awareness on the relationship between the employer's fulfillment of their part of the psychological contract and talent obligations,. The significant and positive interaction of talent status awareness and psychological contract fulfillment in Model 3 (std. $\beta=0.15, p \leq 0.05$ ) provides support for this hypothesis. Controlling for all other independent variables and interactions, Figure 2 shows that the relationship between psychological contract fulfillment and talent obligations is indeed more strongly positive for self-aware talent as compared to talent who are unaware of their status.

Hypothesis $2 \mathrm{a}$ proposed that talent status awareness would also positively moderate the relationship between talent obligations and performance appraisals linked to rewards. Model 3 shows no support for this (std. $\beta=0.00, p>0.05)$.

Hypothesis $2 \mathrm{~b}$, which proposed that the relationship between talent obligations and target setting and evaluation in performance appraisal will be weaker for self-aware talent compared to unaware talent was supported in Model 3 (std. $\beta=-0.22, p \leq 0.05$ ). Figure 3 illustrates this and shows that there is a much stronger positive association among talent who are unaware of their exclusive status compared to self-aware talent.

\section{- INSERT FIGURES 2, 3 \& 4 ABOUT HERE -}

Hypothesis 3, predicting a positive moderation effect of talent status awareness on the relationship between leadership development practices and talent obligations was supported in Model 3 (std. $\beta=$ $0.20, p \leq 0.05)$. Figure 4 illustrates this moderation showing that for self-aware talent the relationship between leadership development practices and talent obligations is more strongly positive than for unaware talent.

Finally, to enhance the interpretation of the slopes shown in Figures 2-4, we compared each of the six slopes to zero based on the procedures described by Cohen, Cohen, West and Aiken 
(2003). The results (Table 4) show that the slopes for the relationships between Psychological contract fulfilment and Talent obligations (in Figure 2) and, respectively, Leadership development practices and Talent obligations (in Figure 4), were significantly different from zero only for Aware Talent. In contrast, the relationship between Target setting and evaluation in Performance appraisal and Talent obligations (in Figure 3) was significantly different from zero only for Unaware Talent.

- INSERT TABLE 4 ABOUT HERE -

\section{DISCUSSION AND CONCLUSIONS}

In this paper, we sought to answer the research question "Do talent who are aware of their exclusive status respond differently to employer inducements compared to unaware talent?". Whereas previous research has indicated that subjective and objective talent status has positive direct effects on employee attitudes (Björkman et al., 2013; Gelens et al., 2014; for an exception see Dries et al, 2014), our results paint a more complex picture. It suggests that, rather than having a direct effect on obligations, status awareness influences how talent respond to organizational inducements, thus changing the effect of the latter on obligations. This has important implications for the theorization of the effects of talent status awareness, the communication of talent status and the management of talent.

First, our finding that self-aware talent, as compared to unaware talent, respond more strongly to both psychological contract fulfilment and leadership development practices indicates that talent status awareness makes talent considerably more sensitive to what companies offer them in return for their acknowledged value. Both of these results extend earlier findings that talent expect employer investments in their future career (Dries \& De Gieter, 2014) by suggesting that the act of informing talent about their status, in itself, is likely to raise talents expectations concerning their employment relationship. 
With respect to performance management, our study suggests that talent status awareness makes the use of target setting and provision of evaluative feedback a significantly less effective management tool for nurturing talent obligations. We explain this by the fact that when talent become aware of their exclusive status they are not only likely to become more self-assured, self-efficacious and self-directed, but also more self-satisfied, perhaps even arrogant and complacent (Bothner et al., 2012; cf. Pfeffer, 2001). We argue that these challenges in managing self-aware talent's performance are more likely to occur within static, non-tournament-style TM systems (which are more commonplace) than tournamentlike ones where talent status can change year on year. However, the latter systems may have their own challenges as discussed below.

Contrary to our expectations, we found no moderation effect of talent status awareness on the relationship between talent obligations and performance appraisal linked to rewards; in other words, self-aware talent are no more responsive in this regard than unaware talent. A possible explanation is that self-aware talent may on average, be more prone to worry about not being able to keep up their level of performance, even as the status awareness also tends to make them more confident. Some support for this conjectured attenuating effect is provided by findings that high status ultimately tends to be associated with weakening performance over time (Bothner et al., 2012) and that status loss, and even the fear of status loss (cf. Pettit et al., 2010), can be detrimental to employees' performance (Marr \& Thau, 2014).

In sum, our results contribute to research on TM in two important ways. First, in contrast to much extant research (Björkman et al., 2013; Gelens et al., 2014; Sonnenberg et al., 2014), our study strongly suggests that we need to account for a combination of status awareness and organizational inducements in order to properly understand the effects of status awareness on talent attitudes such as their obligations towards the employer. This provides substantive support for the conjecture that talent attitudes may not be "only affected by the high potential label itself, but also by the amount and type of resources that follow" (Gelens et al., 2014: 170). It thus suggests that theorizing the specific effects of talent reactions 
to their talent status based on direct reciprocation (Björkman et al., 2013; Gelens et al., 2014; cf. Swailes \& Blackburn, 2016) is not sufficient. Second, we show that talent status awareness among talent is associated with a differential sensitivity to a set of specific employer inducements, consistent with a range of psychological reactions among self-aware talent, both in the form of increased confidence and expectations as well as self-satisfaction and complacency. In this way the study also helps us understand the fears among employers that self-aware talent may become arrogant and complacent (Göbel-Kobialka, 1998; cf. Dries \& De Gieter, 2014).

\section{Practical implications}

The present study calls into question recent evidence that talent status awareness is straightforwardly positively related to talent attitudes (Björkman et al., 2013; Cappelli \& Keller, 2014; McDonnell et al., 2017) and thereby calls into question any clear recommendation that talent status should be communicated, even to talent only. Our study also deepens our understanding of how delicate an issue $\mathrm{TM}$ is. On the one hand, non-transparent communication of talent status has its disadvantages, potentially increasing talent turnover (Dries and De Gieter, 2014; cf. Björkman et al., 2013) and negatively influencing psychological contract fulfillment by creating incongruent perceptions of talent status (Sonnenberg et al., 2014). On the other hand, our findings suggest that if employers communicate talent status to their identified talent, then they also need to deal with the increased expectations concerning organizational inducements such as psychological contract fulfilment and leadership development opportunities. Otherwise they risk losing the commitment-effects of the communication. In addition, the employer may need to carefully deal with increased challenges to manage the performance of self-aware talent given their arguable tendency to become more self-confident, possibly even self-satisfied and arrogant (c.f. Göbel-Kobialka, 1998; cf. Dries \& De Gieter, 2014). Overall this study provides some first-hand evidence concerning the key question of what organizations 
implementing TM need to face up to, and do, to "maximise the contributions" of their talent (McDonnell et al., 2017: 116) given that they tend to become aware of their status.

It is important to note, however, that the above effects of talent status awareness are logically likely to vary between individuals and depend both on the type of TM system employers implement and on how talent status is communicated to employees. For example, in some contexts and among some individuals the reactions may be quite different to those examined in the present study (Petriglieri \& Petriglieri, 2017). We also note that the explained variance and differences in effect size in the present study are limited, albeit clearly significant and fully comparable to moderation research on other topics. While more research is needed to better understand both the contextual dependence and practical significance of our specific results, what stands more firmly is our calling into question the straightforwardly positive effects of talent status awareness and transparent talent communication.

\section{Limitations and future research}

Our study involves a number of limitations. First, we should urge caution in drawing causal conclusions based on our cross-sectional study. Second, we cannot entirely exclude effects of common method bias, although such bias cannot explain the significant moderations that we found (Siemsen, Roth \& Oliveira, 2010). Third, job-related differences, supervisor-related differences, or individual differences beyond our control variables may have influenced our interactions. For example, in line with previous research we studied talent based on unknown organizational criteria of high potentials. This may hide substantive variation in the talent and their attitudes and sensitivities. Based on larger samples future research may also find differences between talent that actively believe they are not identified and talent that are unsure of their identification. Fourth, evident heterogeneity bias may have resulted from the fact that we did not have detailed data on financial reward packages or promotions. Fifth, although our sample included several talent nationalities it was limited to talent working for Finnish companies. This Nordic cultural setting may have influenced the results, perhaps mainly by an increased prevalence 
of non-tournament-style TM systems and a higher degree to which open talent communication is avoided. However, given that neither of these phenomena is uncommon in other cultures, we see no obvious reason to suspect that our findings would be culturally biased. Finally, in this study we did not have adequate data either on the ways in which the employers may implicitly or explicitly have communicated talent status, nor on the type of TM system they implemented. In our view, these last two limitations provide particularly important areas of future research.

Unfavorable psychological reactions to talent status awareness, such as increased expectations and self-satisfaction may be attenuated, or entirely avoided, if an organization implements a tournamentstyle TM system in combination with clearly communicating talent status to both talent and non-talent. To shed more light on the effects of such TM systems, research on status and status dynamics can enrich future research beyond what we have built on in the present study. This research stream has identified complex, tournament-related dynamic effects of having status (Bothner et al., 2012), of competing for status (e.g. Bothner et al., 2007; cf. Bothner, Podolny and Smith, 2011), of gaining status (Bendersky and Shah, 2012) and of losing status (Marr \& Thau, 2014). Similar mechanisms are also likely to be present in the domain of TM. Status research has also recently been used to shed light on the complexity (Kehoe et al., 2016) and duality (Kehoe \& Tzabbar, 2015) of the effects of star performers on the rest of the organization. Extant status research thus provides interesting and important avenues for future research both on the psychological reactions to TM and its impact beyond such reactions. 


\section{REFERENCES}

Bendersky, C. \& Shah, N.P. (2012). 'The Cost of Status Enhancement: Performance Effects of Individuals' Status Mobility in Task Groups.' Organization Science 23: 2, 308-322.

Berger, J., M. H. Fisek, R. Z. Norman, M. Zelditch Jr. (1977). Status Characteristics and Social Interaction: An Expectation-States Approach. Greenwood, Westport, CT.

Björkman, I., Ehrnrooth, M., Mäkelä, K., Smale, A., \& Sumelius, J. (2013). 'Talent or not? Employee reactions to talent identification.' Human Resource Management, 52: 2, 195-214.

Bothner, M.S., Kang, J. \& Stuart, T.E. (2007). 'Competitive Crowding and Risk Taking in a Tournament: Evidence from NASCAR Racing.' Administrative Science Quarterly, 52: 2, 208-247

Bothner, M.S., Kim, Y-K. \& Smith, E.B. (2012). 'How Does Status Affect Performance? Status as an Asset vs. Status as a Liability in the PGA and NASCAR.' Organization Science, 23: 2, 416-433.

Bothner, M.S., Podolny, J.M. \& Smith, E. (2011). 'Organizing contests for status: The Matthew effect versus the Mark effect.' Management Science, 57: 3, 439-457.

Bournois, F. and Rousillon, S. (1992), 'The management of high flyer executives in France'. Human Resource Management Journal, 3: 1, 37-56.

Cappelli, P. \& Keller, J.R. (2014). 'Talent management: Conceptual approaches and practical challenges.' Annual Review of Organizational Psychology and Organizational Behavior, 1: 305331.

Chen, Y-R., Randall S. Peterson, R.S., Phillips, D.J., Podolny, J.M. \& Ridgeway, C.L. (2012). 'Introduction to the Special Issue: Bringing Status to the Table-Attaining, Maintaining, and Experiencing Status in Organizations and Markets.' Organization Science, 23: 2, 299-307. 
Chiang, F. F., \& Birtch, T. A. (2010). 'Appraising Performance across Borders: An Empirical Examination of the Purposes and Practices of Performance Appraisal in a Multi-Country Context. Journal of Management Studies, 47: 7, 1365-1393.

Coyle-Shapiro, J. A.-M., \& Conway, N. (2005). 'Exchange relationships: Examining psychological contracts and perceived organizational support.' Journal of Applied Psychology, 90: 4, 774-781.

Coyle-Shapiro, J. A.-M., \& Shore L. M. (2007). 'The employee-organization relationship: Where do we go from here?' Human Resource Management Review, 17: 2, 166-179.

Cohen, J., Cohen, P., West, S. G., \& Aiken, L. S. (2003). Applied multiple regression-correlation analysis for the behavioral sciences (3rd ed.). Mahwah, NJ: Erlbaum.

Dries, N. (2013). 'From phenomenon to theory: Introduction to the Special Issue.' Human Resource Management Review, 23: 4, 267-271.

Dries, N. \& De Gieter, S. (2014). 'Information asymmetry in high potential programs: A potential risk for psychological contract breach,' Personnel Review, 43: 1, 136-162.

Dries, N. \& Pepermans, R. (2008). ' Real' high potential careers: an empirical study into the perspectives of organizations and high potentials.' Personnel Review, 3: 1, 85-108.

Dries, N., Forrier, A., De Vos, A. \& Pepermans, R. (2014). 'Self-perceived employability, organizationrated potential, and the psychological contract.' Journal of Managerial Psychology. 29: 5, 565-581.

Evans, P.A.L, Pucik, V. and Björkman, I. (2010) The Global Challenge: International Human Resource Management, $2^{\text {nd }}$ edn., Chicago: McGraw-Hill.

Gallardo-Gallardo, E., Dries,N., \& González-Cruz, T. F. (2013).'What is the meaning of 'talent' in the world of work?' Human Resource Management Review, 23: 4, 290-300.

Gelens, J., Hofmans, J., Dries, N. and Pepermans, R. (2014). 'TM and organizational justice: employee reactions to high potential identification.' Human Resource Management Journal, 24: 2, 159-175. 
Göbel-Kobialka, S. (1998). 'Reaching business excellence through sound people management.' European Journal of Work and Organizational Psychology, 7: 4; 549-556.

Hom, P.W., Tsui, A.S., Wu, J.B., Lee, T.W., Zhang, A.Y., Fu, P.P. \& Li, L. (2011). 'Explaining employment relationships with social exchange and job embeddedness.' Journal of Applied Psychology, 94: 2, 277-297.

Kehoe, R.R. \& Tzabbar, D. (2015). 'Lighting the way of stealing the shine? An examination of the duality in star scientists' effects on firm innovative performance.' Strategic Management Journal, 36: 709-727.

Kehoe, R.R., Lepak, D.P. \& Bentley, F.S. (2016). 'Let's Call a Star a Star: Task Performance, External Status, and Exceptional Contributors in Organizations.' Journal of Management, DOI: $10.1177 / 0149206316628644$

Khoreva, V. (2016). 'Leadership Development Practices as driver of employee attitudes.' Journal of Managerial Psychology, 31: 2, 537 - 551

LeBreton, J.M. \& Senter, J.L. (2008). 'Answers to 20 Questions About Interrater Reliability and Interrater Agreement.' Organizational Research Methods, 11: 4, 815-852.

Lee, C: Liu, J., Rousseau, D.M., Hui, C. \& Chen, Z.X. (2011). 'Inducements, contributions, and fulfillment in employee psychological contracts.' Human Resource Management, 50: 2; 201-226.

Lount Jr., R.B. \& Pettit, N.C. (2012). The social context of trust. The role of status. Organizational Behavior and Human Decision Processes 117: 15-23

Malik, A.R. \& Singh, P. (2014). 'High potential' programs: Let's hear it for 'B' players.' Human Resource Management Review, 24: 330-346.

Marescaux, E., DeWinne, S. \& Sels, L. (2013). 'HR practices and affective organizational commitment: (when) does HR differentiation pay off?' Human Resource Management Journal, 23: 4, 329-345. 
Marr, J.C. \& Thau, S. (2014). 'Falling from great (and not-so-great) heights: How initial status position influences performance after status loss.' Academy of Management Journal, 57: 1, 223-248.

McDonnell, A., Collings, D.G., Mellahi, K. \& Schuler, R. (2017). Talent management: a systematic review and future Prospects. European Journal of International Management, 11:1, 86-128.

Muthén, L. K. \& Muthén, B. O. (1998-2007). Mplus user's guide: Statistical analysis with latent variables (5th Ed.). Los Angeles, CA: Muthén \& Muthén.

Pettit, N. C., Yong, K., \& Spataro, S. E. (2010). Holding your place: Reactions to the prospect of status gains and losses. Journal of Experimental Social Psychology, 46: 396-401.

Petriglieri, J.L. \& Petriglieri, G. (2017). The talent curse. Harvard Business Review, May-June.

Pfeffer, J. (2001). 'Fighting the War for Talent is Hazardous to Your Organization's Health.' Organizational Dynamics, 29: 4; 248-259.

Robinson, S. (1996). Trust and breach of the psychological contract. Administrative Science Quarterly, $41: 4,574-599$.

Robinson, S.L. \& Morrison, E.W. (2000). The development of psychological contract breach and violation: a longitudinal study. Journal of Organizational Behavior, 21: 525-546

Rousseau, D.M. (2000). Psychological contract inventory: Technical report (3rd ed.). Pittsburgh, PA: Carnegie Mellon University.

Rousseau, D.M. (1995). Psychological contracts in organizations: Understanding written and unwritten agreements. Thousand Oaks: Sage.

Rynes, S.L., Gerhart, B. \& Parks, L. (2005). 'Personnel psychology: Performance evaluation and pay for performance.' Annual Review of Psychology, 56: 1, 571-600.

Shaw, J.D., Dineen, B.R., Fang, R. \& Vellella, R.F. (2009). 'Employee-Organization Exchange Relationships, HRM Practices, and Quit Rates of Good and Poor Performers.' Academy of Management Journal, 52: 5, 1016-1033. 
Siemsen, E., Roth, A. \& Oliveira, P. (2010). 'Common Method Bias in Regression Models With Linear, Quadratic, and Interaction Effects.' Organizational Research Methods, 13: 3, 456-476.

Silzer, R.F. \& Church, A.H. (2010). 'Identifying and assessing high potential talent: current organizational practices.' In Silzer, R.F. \& Dowell, B.E. (Eds), Strategy Driven TM: A Leadership Imperative, Jossey Bass, San Francisco, CA.

Sonnenberg, M., van Zijderveld, V. \& Brinks, M. (2014). 'The role of talent-perception incongruence in effective TM.' Journal of World Business, 49: 272-280.

Swailes, S. \& Blackburn, M. (2016),"Employee reactions to talent pool membership", Employee Relations, 38(1): 112-128

Tierney, P. \& Farmer, S.M. (2004). The Pygmalion Process and Employee Creativity, Journal of Management, 30: 3, 413-432.

Webster, M., Jr., D. R. Entwisle. (1976). 'Expectation effects on performance evaluations.' Social Forces 55: 2, 493-502.

Whiteley, P., Sy, T. \& Johnson, S.K. (2012) Leaders' conceptions of followers: Implications for naturally occurring Pygmalion effects. The Leadership Quarterly, 23: 822-834.

Williams, L. J., Vandenberg, R. J., \& Edwards, J. R. (2009). 'Structural equation modeling in management research: A guide for improved analysis.' The Academy of Management Annals, 3: 1, 543-604. 


\section{Table legends and Figure legends}

TABLE 1 Sample demographics

TABLE 2 Means, standard deviations and correlations

TABLE 3 Linear Mixed Model regressions

TABLE 4 Tests of Simple Slopes of interaction effects

FIGURE 1 The conceptual model

FIGURE 2 Moderation effect of talent status awareness and psychological contract fulfillment

FIGURE 3 Moderation effect of talent status awareness and target setting and evaluative feedback in performance appraisal

FIGURE 4 Moderation effect of talent status awareness and leadership development practices 
TABLE 1

\section{Sample demographics}

Talent Status Awareness

\begin{tabular}{lll}
\hline & Aware & Unaware \\
\hline Gender & $108(73.0)$ & $132(72.1)$ \\
Male (\%) & $40(27.0)$ & $49(26.8)$ \\
Female (\%) & $17(11.5)$ & $22(12.0)$ \\
\hline Age & $40(27.0)$ & $47(25.7)$ \\
$<30(\%)$ & $46(31.1)$ & $42(23.0)$ \\
$31-35(\%)$ & $21(14.2)$ & $43(23.5)$ \\
$36-40(\%)$ & $14(9.5)$ & $17(9.3)$ \\
$41-45(\%)$ & $9(6.1)$ & $12(6.6)$ \\
$46-50(\%)$ & & \\
$51-(\%)$ & $1(0.7)$ & $4(2.2)$ \\
\hline Tenure Corporation & $2(1.4)$ & $10(5.5)$ \\
$0-6$ months (\%) & $22(14.9)$ & $28(15.3)$ \\
$7-12$ months $(\%)$ & $46(31.1)$ & $63(34.4)$ \\
$1-2$ years (\%) & $40(27.0)$ & $37(20.2)$ \\
$3-5$ years (\%) & $36(24.3)$ & $40(21.9)$ \\
$6-10$ years (\%) & & \\
$11+$ years (\%) & $23(15.5)$ & $16(8.7)$ \\
\hline Organisation & $9(6.4)$ & $5(2.7)$ \\
$1(\%)$ & $16(10.8)$ & $0(0.0)$ \\
2 (\%) & $18(12.2)$ & $22(12.0)$ \\
3 (\%) & $9(6.1)$ & $32(17.5)$ \\
$4(\%)$ & $21(14.2)$ & $33(18.0)$ \\
$5(\%)$ & $31(20.9)$ & $35(19.1)$ \\
6 (\%) & $19(12.8)$ & $40(21.9)$ \\
$7(\%)$ & $144(44.8)$ & $177(55.2)$ \\
$8(\%)$ & & \\
\hline Total N (complete responses) (\%)1 $\%$ & 30 \\
\hline Nationality & & \\
Number of different nationalities & & \\
\hline & & \\
\hline
\end{tabular}

${ }^{1}$ Total responses was 332 but one respondent did not report status awareness. Other missing values explain the differences between complete $\mathrm{N}$ and $\mathrm{N}$ within the various categories. 
TABLE 2

Means, standard deviations and correlations

\begin{tabular}{|c|c|c|c|c|c|c|c|c|}
\hline Variable & $\begin{array}{c}\text { Mean } \\
\text { (median) }\end{array}$ & S.D. & 1 & 2 & 3 & 4 & 5 & 6 \\
\hline 1. Talent Obligations & 5.62 & .84 & & & & & & \\
\hline 2. Psychological contract fulfilment & 4.83 & 1.37 & $.13 * *$ & & & & & \\
\hline $\begin{array}{l}\text { 3. Connection between performance } \\
\text { appraisal and rewards }\end{array}$ & 4.16 & 1.40 & $.17 * *$ & $.29 * *$ & & & & \\
\hline $\begin{array}{l}\text { 4. Target setting and evaluative } \\
\text { feedback in performance appraisal }\end{array}$ & 5.09 & 1.21 & $.15^{* *}$ & $.23 * *$ & $.69^{* *}$ & & & \\
\hline 5. Leadership development practices & 3.33 & 0.96 & $.13 * *$ & $.32 * *$ & $.32 * *$ & $.20^{* *}$ & & \\
\hline 6. Talent status awareness & $-{ }^{1}$ & & $.19 * *$ & $.10^{*}$ & $.14^{*}$ & $.13^{* *}$ & $.19 * *$ & \\
\hline 7. Age & $\begin{array}{l}(36-40 \\
\text { years })\end{array}$ & $-^{2}$ & -.01 & .01 & .08 & $.11^{*}$ & $.15^{* *}$ & .0 \\
\hline 8. Tenure Corporation & $\begin{array}{l}(4-10 \\
\text { years })\end{array}$ & $-^{2}$ & $-.10^{*}$ & .01 & -.04 & -.01 & .03 & .11 \\
\hline
\end{tabular}

* Correlation is significant at the 0.05 level (2-tailed).

** Correlation is significant at the 0.01 level (2-tailed).

${ }^{1}$ Mean (median) not meaningful as the Talent Status Awareness is a dichotomous variable.

${ }^{2}$ Standard deviation not meaningful as Age and Tenure are factorial variables. 
TABLE 3

Linear Mixed Model regressions

Dependent variable:

Model 11

Model 2

Model 3

Talent obligations

$\beta \quad$ p-value

$\beta \quad \mathrm{p}$-value

$\beta \quad \mathrm{p}$-value

Intercept: Organization ( $\mathrm{N}=8)$ as blocking

variable $^{1}$

$5.665 .000 * * *$

$5.042 .000^{* * *}$

$5.023 \quad .000 * * *$

Individual-level controls (factors) ${ }^{2}$

Age

.823

Nationality ${ }^{3}$

.203

.804

Gender

.309

.130

Tenure corporation

.372

.520

.305

\section{Independent variables (covariates)}

Psychological contract fulfilment

Connection between performance appraisal

and rewards

Target setting and evaluative feedback in

performance appraisal

$.09 .016^{*}$

$.11 .018^{*}$

Leadership development practices

$.09 \quad .050^{*}$

$.17 .005^{* *}$

Talent status awareness (dummy)

$.09 .050^{*}$

$-.00 \quad .941$

$.16 \quad .076$

$-.14 \quad .758$

\section{Moderations}

Talent status awareness * Psychological

contract fulfilment

$.15 \quad .036^{*}$

Talent status awareness $*$ Connection

between performance appraisal and

extrinsic rewards

$.00 \quad .981$

Talent status awareness * Target setting and evaluative feedback in performance appraisal

Talent status awareness * Leadership development practices

$.20 \quad .032^{*}$

\begin{tabular}{lccc}
$-2 \mathrm{LL}$ & 824.1 & 704.2 & 690.7 \\
$\Delta-2 \mathrm{LL}$ & $4.3^{*}$ & $3.1^{\#}$ & $4.6^{*}$ \\
Pseudo $\mathrm{R}^{2}$ (indexed relative to model 0) & & 0,28 & 0,33 \\
$\mathrm{~N}$ & 321 & 321 & 321 \\
$\mathrm{df}$ & 3 & 53 & 57 \\
\hline
\end{tabular}

Two-sided test: $* \mathrm{p} \leq 0.05 ; \quad * * \mathrm{p} \leq 0.01 ; \quad * * * \mathrm{p} \leq 0.001$

${ }^{1}$ Model 1 includes a random intercept (for level-2). Model 1 is compared against a model (not shown) with only a fixed intercept $=>$ It shows a significant difference between level-2 units (organizations).

${ }^{2}$ As the control variables are all categorical they do not have only one $\beta$-coefficient, but a set of coefficients for each dummy. These are not reported. The p-values correspond to Type III test of fixed effects for each variable.

${ }^{3}$ As the number of dummies for respondent nationalities was high compared to the sample size we also ran the models without these dummies. This did not change the results 
TABLE 4

Tests of Simple Slopes of interaction effects

\begin{tabular}{lrrr} 
& $\beta$ & $\begin{array}{r}\mathrm{t} \text {-value } \\
\text { of slope }\end{array}$ & $\begin{array}{r}\mathrm{p} \text {-value } \\
\text { of slope }\end{array}$ \\
\hline $\begin{array}{l}\text { Aware Talent, Psychological contract fulfillment } \\
\text { Unaware Talent, Psychological contract fulfillment }\end{array}$ & $\begin{array}{r}.12 \\
-.03\end{array}$ & $\begin{array}{r}-.191 \\
-.671\end{array}$ & $\begin{array}{r}.029^{*} \\
\text { ins. }\end{array}$ \\
\hline $\begin{array}{l}\text { Aware Talent, Target setting and evaluative feedback in performance appraisal } \\
\text { Unaware Talent, Target setting and evaluative feedback in performance appraisal }\end{array}$ & $\begin{array}{r}-.05 \\
.17\end{array}$ & $\begin{array}{r}-.913 \\
\text { ins. }\end{array}$ & $.002^{* *}$ \\
\hline Aware Talent, Leadership development practices & .20 & 3.162 & $.002^{* *}$ \\
Unaware Talent, Leadership development practices & .00 & .000 & ins. \\
\hline
\end{tabular}

Two-sided test: $* \mathrm{p} \leq 0.05 ; \quad * * \mathrm{p} \leq 0.01$ 
FIGURE 1

The conceptual model

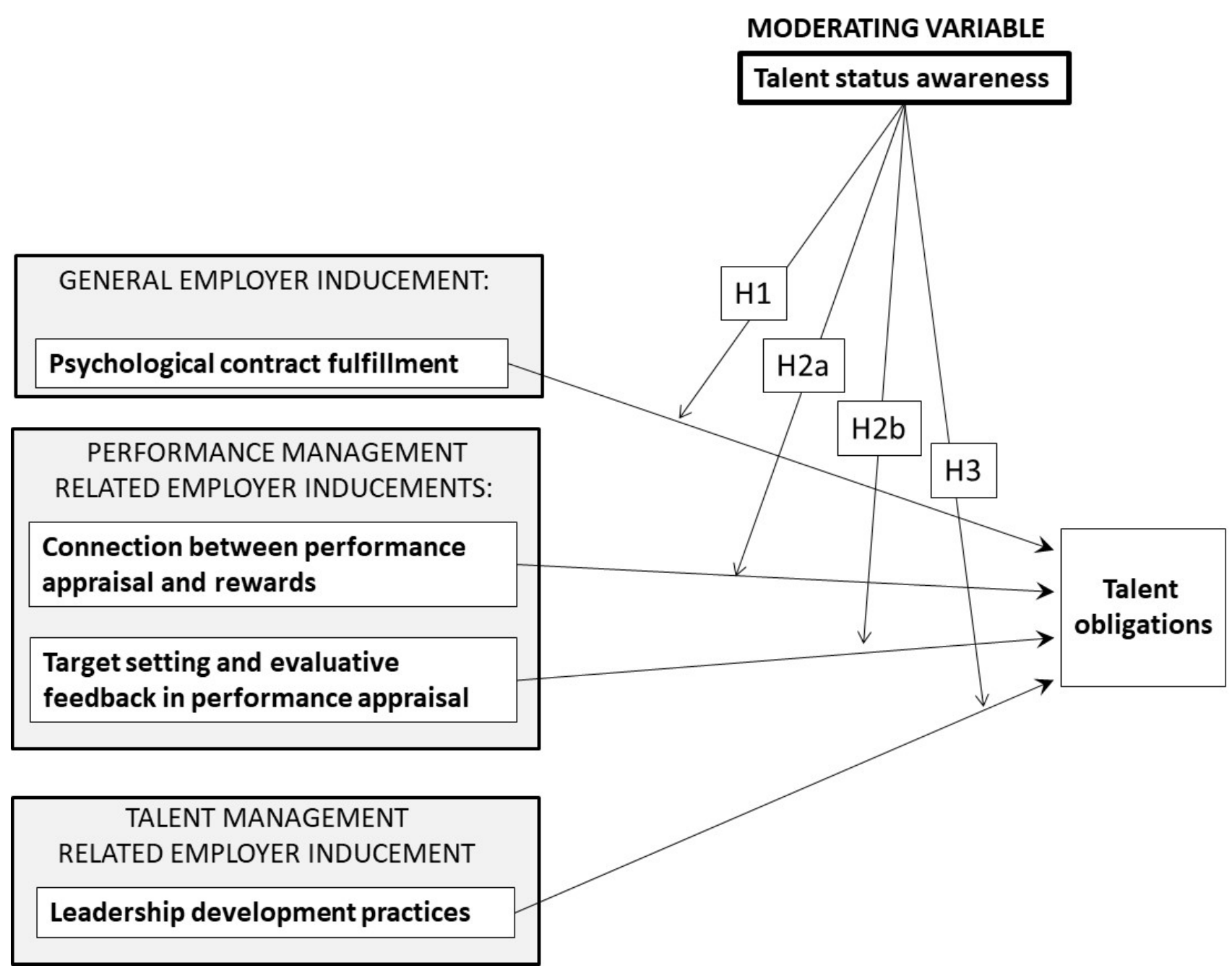


FIGURE 2

Moderation effect of talent status awareness and psychological contract fulfillment

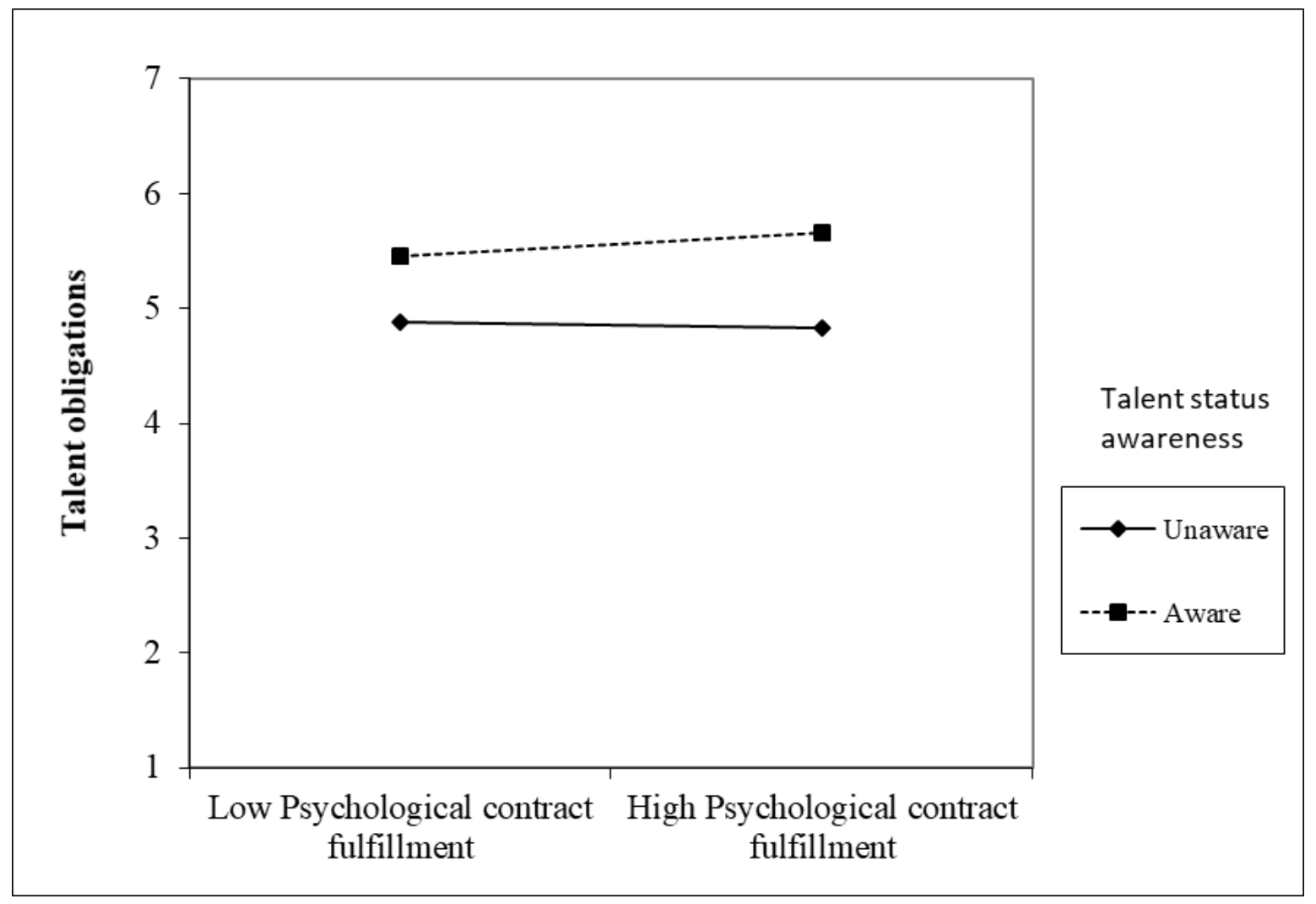


FIGURE 3

Moderation effect of talent status awareness and target setting and evaluative feedback in performance appraisal

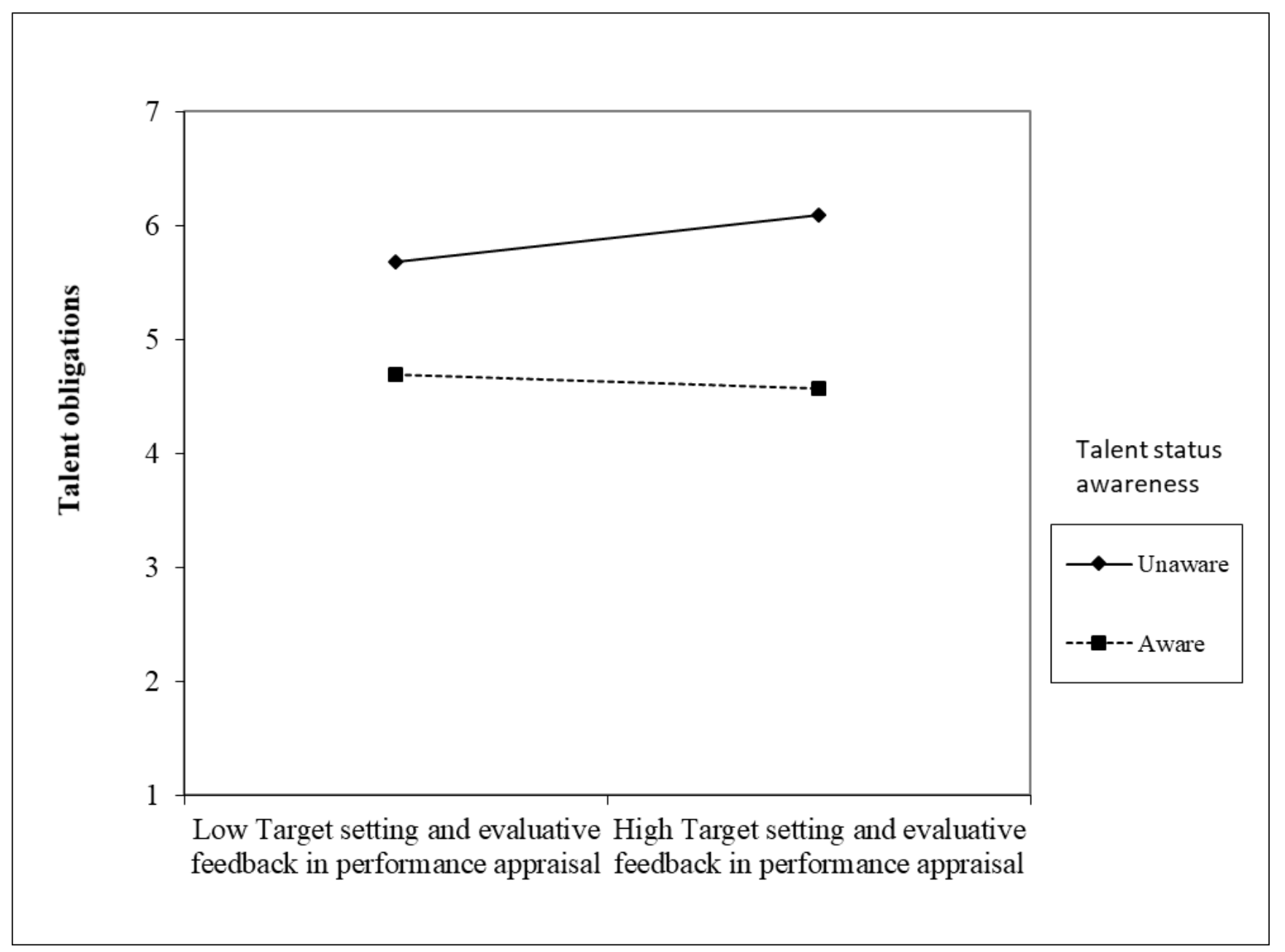


FIGURE 4

Moderation effect of talent status awareness and leadership development practices

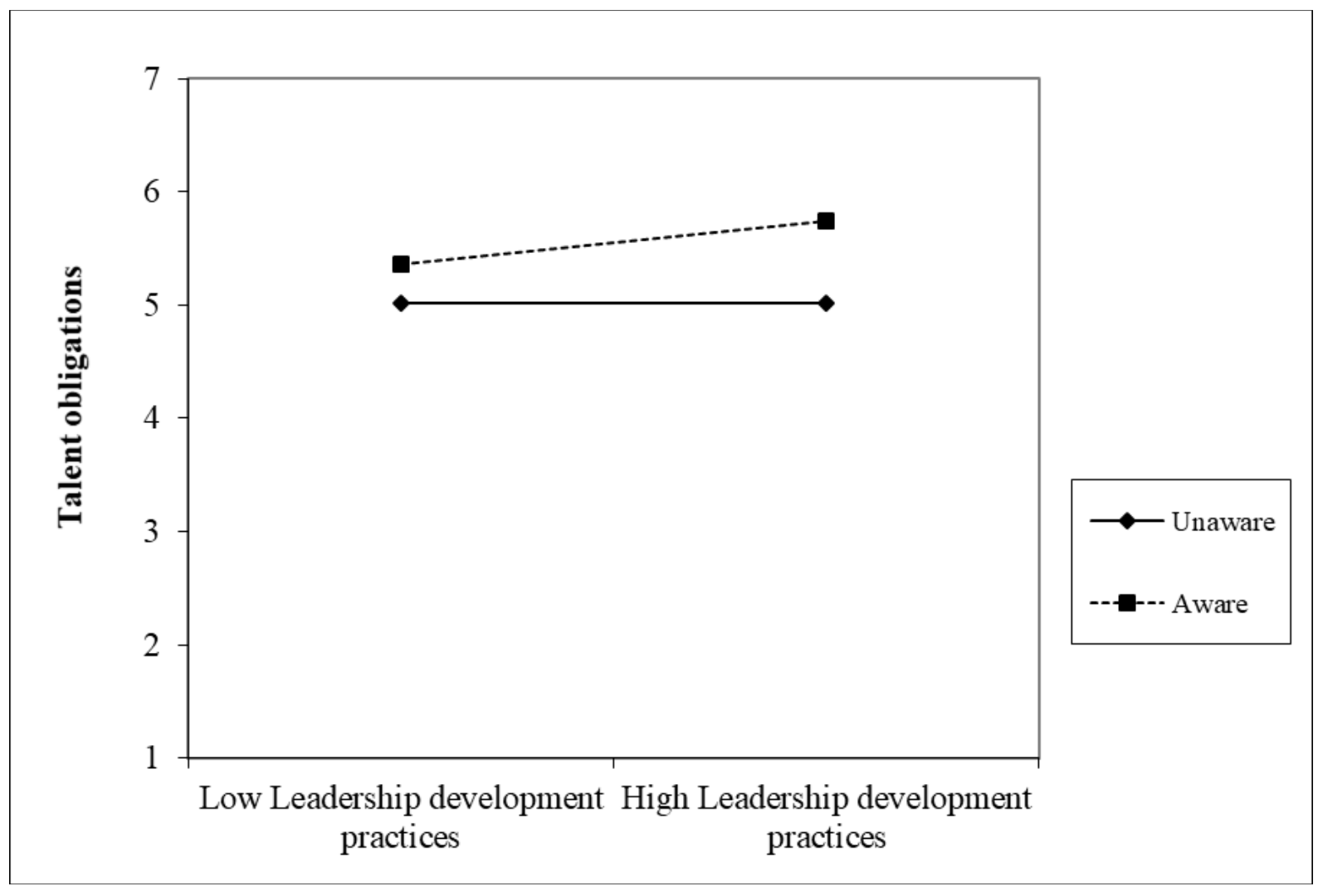

